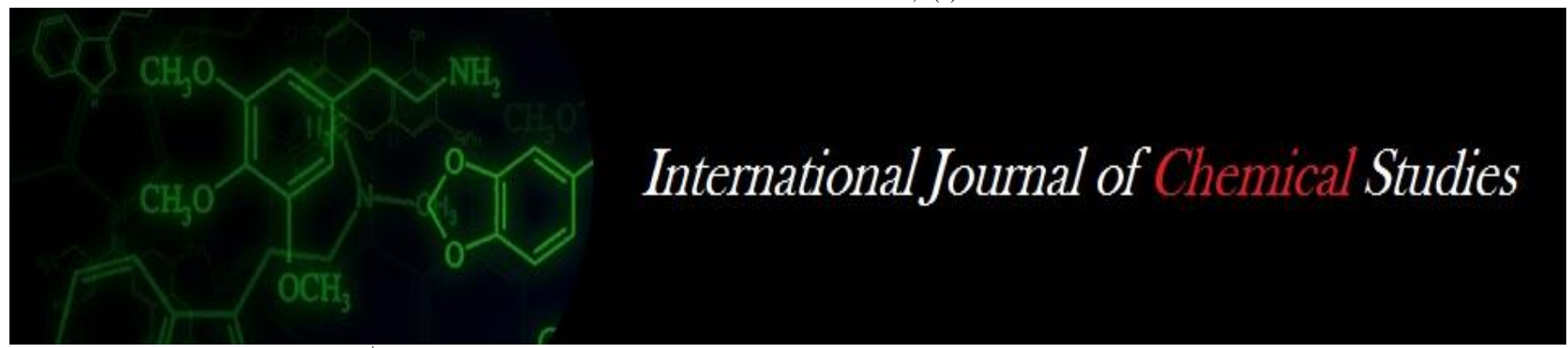

P-ISSN: 2349-8528

E-ISSN: 2321-4902

www.chemijournal.com

IJCS 2020; 8(6): 2855-2857

(C) 2020 IJCS

Received: 01-09-2020

Accepted: 05-10-2020

Dr. Puspita Das

College of Community Science,

Central Agricultural University,

Tura, Meghalaya, India

Dr. Shipra Nagar

College of Community Science,

Central Agricultural University,

Tura, Meghalaya, India
Corresponding Author: Dr. Puspita Das

College of Community Science,

Central Agricultural University,

Tura, Meghalaya, India

\section{Food practices of Garo Hills Meghalaya and harmful effects of Sodium Bicarbonate}

\author{
Dr. Puspita Das and Dr. Shipra Nagar
}

DOI: $\underline{\text { https://doi.org/10.22271/chemi.2020.v8.i6ao.11258 }}$

\begin{abstract}
Food practices of tribal population of Garo Hills of Meghalaya are distinct and are characterized by definite areas with specific food habits, dialects and cultural homogeneity. Being simple in nature, the people in Garo Hills of Meghalaya have simple food practices and rice is mainly the staple food along with different kinds of non-vegetarian delicacies. One of the characteristic feature found among Garo families is use of soda or Sodium bicarbonate in their dishes during cooking which poses a threat to their health. The region also has the highest prevalence of anaemia found among women and children. This paper discusses harmful effects of use of Sodium bicarbonate in food and the food practices of people of Garo Hills of Meghalaya.
\end{abstract}

Keywords: Sodium bicarbonate, food, Garo, Meghalaya, anaemia

\section{Introduction}

Meghalaya is one of the seven states of the North Eastern region of India and was carved out of Assam in the year 1972 as an autonomous state. The state primarily consists of three distinct hill ranges, viz. Garo hills, Khasi hills and Jaintiya hills. Thus the people living here are mainly of three tribes - Garos, Khasis and Jaintiyas, each having distinct pattern of culture, traditions, festivals and food. Meghalaya is famous for its matrilineal culture in which women take on the family lineage and property, thus keeping them in the position of decision makers.

Rice is the staple food of people of the state along with meat or fish preparations. Other crops like maize, tapioca, different types of green leafy vegetables, bamboo shoots are also eaten. Besides this, people here rear goats, pig, ducks, fowls and consume their meat, Fish, crabs, eels, prawns, dry fishes also form a major part of the food in Meghalaya. A characteristic habit of the people of Meghalaya is chewing Betel leaf and unripe betel nut. In Meghalaya, the rice beer is prepared by fermenting the rice, and then distilling it.

The food habits of the people of Garo Hills are a little different due to their own traditional customs. They eat foods collected from natural sources free from any kind of adulteration. Cooking is easy and in a simple way. The staple food of people in Garo hills is also rice but they also eat fish, meat, millets, maize and various other vegetables including bamboo shoots, mushrooms, mustard leaves, etc. Variety of meats of ducks, fowl, hare and swine are used. Food recipes made of pork, such as dried pork or smoked meat are very much relished by people in this region. Nakham (dry fish) is favorite of the Garos. Apart from other drinks, locally brewed liquor plays an important role in the life of the Garos. They use a kind of potash in curries, which they obtain by burning dry pieces of plaintain stems or young bamboos locally known as Kalchi or Katchi. After they are burnt, the ashes are collected and are dipped in water and are strained in conical shaped in bamboo strainer. But nowadays, this is replaced by soda which is now added frequently to their preparations and this is where the problem lies. Sodium bicarbonate (NaHCO3) commonly known as Baking Soda is a chemical compound and has a slightly salty or alkaline taste. It is a salt composed of sodium and bicarbonate. Sodium bicarbonate degrades into carbon dioxide, sodium carbonate and water and with gas production, carbon dioxide causes a faster fermentation (Kaswas et al. 2007) ${ }^{[1]}$.

Sodium bicarbonate has got many uses in the food industry, especially when used as a leavening agent in baking. Medically it is used as antacid to treat local heartburn, indigestion an an upset stomach. However, if taken or ingested regularly, it can be harmful for human body. 
Researches have proved that over-use of sodium bicarbonate in food causes damage to nutrients like Vitamin C, D, riboflavin, thiamin and iron. Some studies have shown that the use of sodium bicarbonate in the flour fermentation process causes the available phytic acid in the flour to enter without breakdown and decreases the absorption of metals such as iron, zinc, calcium, etc. (Norhaizan and Nor Faizadatul, 2009) ${ }^{[2]}$. Sodium bicarbonate reacts with acids in foods especially Vitamin C (ascorbic acid) and makes it unavailable to the body.

As far as the food patterns of the people of Meghalaya is concerned, it seen that rice is the staple food while there is no place of any pulses in the meals, although a lot of non vegetarian items are included in the diet. Nutritional status for the state of Meghalaya, according to the National Family Health Survey - IV conducted by the International Institute for Population Sciences, Mumbai shows a dismal picture. It revealed high rates of childhood under-nutrition with $28.9 \%$ underweight, $43.8 \%$ stunting, $15.3 \%$ wasting, and $71 \%$ of children under five years with anaemia. Among the women, it is 52 per cent and the percentage is higher in the women who are breastfeeding (NHFS, 2015-16). The nutrient intake of women and adolescent girls were found to be far below the Indian recommended levels for energy, protein, fat, calcium, iron, and carotene. A study by Monsang and Singh (2018) ${ }^{[4]}$ revealed that dietary pattern and nutritional knowledge and practices of the women in selected area of Meghalaya were not satisfactory up to the standard of living.

Anaemia is one of the 'silent' conditions that affects the population severely affecting the country's overall economic productivity. Meghalaya is having almost 40.7 percent of children between the age of 6 to 59 months who are anaemic and among all districts, East Garo Hills have three fourth of children $(75.4 \%)$ found to be anaemic which is really a grim picture. A study by Singh et al. (2018) ${ }^{[5]}$ reported maximum nutritional deficiency reported by clinical examination in primary school children in the state was vitamin $\mathrm{C}$ deficiency with the symptoms of spongy and bleeding gums followed by iron deficiency anaemia. The high occurrence of anaemia may be due to faulty food habits, food fads, worm infections, etc. When we see the situation of women (of age 15 to 49 years), about half of the population of India and the state of Meghalaya is anaemic. The situation is worse in the district of West Garo hills where about 71 per cent of women are having low haemoglobin level below 12 . This is being validated through a study by Monsang and Singh (2018) ${ }^{[4]}$, where they found that the prevalence of anemia among the Garo women of Meghalaya was $92 \%$ with higher percentage in moderate anemia.

Prevalence of anaemia among women is often used as an indicator of nutritional well-being of society. Iron deficiency anaemia results from low dietary intake, low absorption or from conditions that cause chronic blood loss (eg. worms, ulcers, etc.). Initially anaemia can be asymptomatic but eventually it can cause weakness, fatigue, pallor, breathlessness, palpitations and headaches. Anaemia can result in maternal mortality, weakness, diminished physical and mental capacity, increased morbidity from infectious diseases, perinatal mortality, premature delivery, low birth weight. Iron deficiency anaemia result from low dietary intake, low absorption or from conditions that cause chronic blood loss (eg. worms or ulcers). Even bioavailability of iron / ability of the body to absorb it as a nutrient can be hampered by the immediate drinking of tea with meal. In the regions of Garo hills of the state, addition of soda in foods is a threatening practice which reduces the total absorption of iron from the body, even if a lot of iron rich foods or non vegetarian items are taken.

The use of chemical soda powder in food was also prohibited by the District Administration of North Garo Hills in the region. Deputy Commissioner of West Garo Hills, Sh. Ram Singh, in one of his addresses during the Poshan Maah in September 2019, warned the people about harmful effects of soda as it inhibits absorption of iron, hence the district have a highest incidence of anaemia amongst women including children. He stressed on the use of 'Kalchi' a locally made solution of bamboo or banana stalks.

Long term and over-use of sodium bicabonte can increase risks for deficiency of potassium (hypokalemia) and chloride in blood (hypochloremia), worsens kidney diseases including heart failure, increases muscle weakness and cramps and aids to increased production of stomach acid. Other harmful effects of use of Sodium bicarbonate in food includes:

a. Iron deficiency anaemia: Sodium bicarbonate decreased iron absorption in the body causing iron deficiency anaemia.

b. High blood pressure: Due to presence of sodium in blood it can increase the blood pressure.

c. Swelling (Oedema): It increases water retention in the body causing swelling due to excess fluid in the body which is harmful for people with health and liver diseases.

d. Diabetic Ketoacidosis: It increases blood ketone in the body and causes complications like ketoacidosis in a Diabetic patients.

Thus it can be seen that use of Sodium bicarbonate during cooking whether green leafy vegetables or non vegetarian items is not only unhealthy but poses a risk of developing different kinds of diseases. The strategies of the Government should focus on delimiting use of this chemical soda or Sodium bicarbonate Here it is worthwhile to mention that involving women and adolescent girls to make them aware of these kinds of faulty food habits should be the need of the hour. The knowledge of women on the importance of eating well and their capacity to implement their priorities in a matrilineal society, like Meghalaya, should prevent the increase of cases in anaemia in women and children. Direct multi-sectoral actions to tackle critical women's nutritional challenges, such as iron deficiency anaemia, need to be rolled out on a larger scale to achieve universal coverage. The different government schemes should provide the micronutrient supplementation which should be made absolutely compulsory. Awareness and demonstrations on methods of proper sanitation and food fortification should be imparted. Adolescents should be given special dietary advice and counseling in the schools. This would make them aware of not only their dietary needs but also of the growing years.

\section{References}

1. Kaswas J. GRCIA-Castillo, R. Garza-Cazares, F. Fimbres-durazo, H. Otivares-Saenz, E. Hernandez Vital, G. et al. Effects of sodium bicarbonate and yeast on productive performance and carcass characteristics of light weight lambs fed finishing diets. Small Ruminant Research 2007;67(2):157-63.

2. Norhaizan M, Norfaizadatul A. Determination of phytate, iron, Zinc, Calcium contents and their molar ratios in commonly consumed raw and prepared food in Malaysia. Malaysian Journal of Nutrition 2009;15(2):213-22 
3. National Family Health Survey (NFHS-4), 2015-16. International Institute of Population Sciences (IIA) and ORC Macro: Mumbai. Retrieved January 21, 2017 from http://www.nfhs.org.

http://rchiips.org/NFHS/factsheet_NFHS-4.shtml

4. Monsang ES, Singh N. Prevalence of Anaemia and Nutritional knowledge among tribal women of reproductive age group of Meghalaya, India. Indian Journal of Current Microbiology and Applied Sciences 2018;7(10):1221-1229.

5. Singh N, Nagar S, Devi RT. Assessment of Micronutrient Deficiencies among primary school children of Meghalaya, India. Asian Journal of Home Science 2018;13(2):532-537. 